\title{
Treatment of Plane Warts with a Low-Dose Oral Isotretinoin
}

\author{
Hayder R. Al-Hamamy, ${ }^{1}$ Husam Ali Salman, ${ }^{1}$ and Nawar A. Abdulsattar ${ }^{2}$ \\ ${ }^{1}$ Department of Dermatology and Venereology, College of Medicine, University of Baghdad, Medical Collection Office, \\ P.O. Box 61211, Baghdad 12114, Iraq \\ ${ }^{2}$ Department of Dermatology and Venereology, Baghdad Teaching Hospital, Medical City, Baghdad, Iraq
}

Correspondence should be addressed to Husam Ali Salman, husjob2000@yahoo.com

Received 22 September 2012; Accepted 21 November 2012

Academic Editors: A. Ingber and A. Zalewska

Copyright ( 2012 Hayder R. Al-Hamamy et al. This is an open access article distributed under the Creative Commons Attribution License, which permits unrestricted use, distribution, and reproduction in any medium, provided the original work is properly cited.

\begin{abstract}
Objective. To assess the efficacy of a low-dose oral isotretinoin in the treatment of plane warts. Patients and Methods. Thirtyone patients with recalcitrant facial plane warts were enrolled. A cumulative dose of $30 \mathrm{mg} / \mathrm{kg}$ for two months of treatment was calculated; this was equal to a mean of $0.5 \mathrm{mg} / \mathrm{kg} /$ day. Each patient was seen every two weeks during the treatment period. Response to treatment was either complete or no response. Patients with complete response were followed up monthly for four months to record the relapse rate. Results. Twenty-six patients completed the study; their ages range from 5 to 35 with a mean \pm SD $15.28 \pm 8.51$ years. Fifteen $(57.69 \%)$ patients were females and eleven $(42.30 \%)$ were males. Nineteen $(73.07 \%)$ patients showed complete response and seven $(26.92 \%)$ patients showed no response at the end of two months of therapy. The difference was statistically significant; $P$ value $<0.0001$. Fifteen $(78.94 \%)$ out of nineteen patients, who had complete response, were still free from warts at the end of four-month followup. Conclusion. Oral isotretinoin is effective in the treatment of recalcitrant facial plane warts.
\end{abstract}

\section{Introduction}

Plane warts are smooth, flat, or slightly elevated and are usually skin coloured or greyish yellow but may be pigmented. They are round or polygonal in shape and vary in size from 1 to $5 \mathrm{~mm}$ or more in diameter. They usually affect the face and the dorsa of the hands [1]. Many modalities of therapy had been used with variable success, for example, topical retinoic acid [2], imiquimod [3], and 5-fluorouracil [4].

Systemic isotretinoin has been used to treat severe acne vulgaris. However, isotretinoin also represents a potentially useful choice in many dermatologic diseases such as psoriasis, pityriasis rubra pilaris, condylomata acuminata, skin cancers, and rosacea [5].

The aim of the present study is to evaluate the effectiveness of a low-dose oral isotretinoin in the treatment of plane warts.

\section{Patients and Methods}

This was an open therapeutic trial conducted at the department of Dermatology and Venereology, Baghdad Teaching hospital from August 2009 to March 2011.
Thirty-one patients with facial plane warts were included in the study. All cases were resistant to other forms of therapy and were without any treatment for at least two months before beginning the study.

All female patients enrolled in the study were unmarried. Children under 5 years and pregnant women were excluded from the study.

A full interrogation and explanation about the nature of the disease and the possible side effects of the treatment were performed to each patient and/or the patient's parent. Then a formal consent was obtained from each patient or his/her parent.

The study was approved by the ethical committee.

Each patient was treated with oral isotretinoin (Retane) capsules from Asia Pharmaceutical Industries, Syria. For each patient a cumulative dose of $30 \mathrm{mg} / \mathrm{Kg}$ for two-month period of treatment was calculated. Then the number of isotretinoin capsules (10 and/or $20 \mathrm{mg}$ ) required for the whole treatment period was calculated accordingly. The number of capsules was divided to 60 days of treatment. This was equal to a mean dose of $0.5 \mathrm{mg} / \mathrm{kg} /$ day.

Each patient was instructed to use white petrolatum jelly (Vaseline) as needed to reduce lip dryness. 


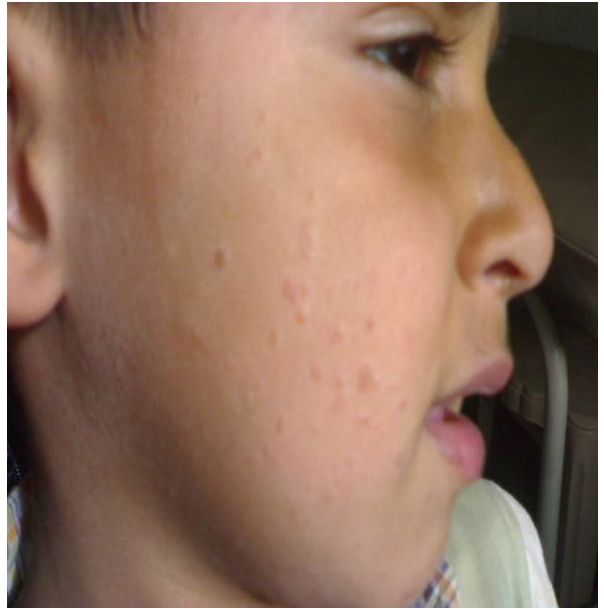

(a)

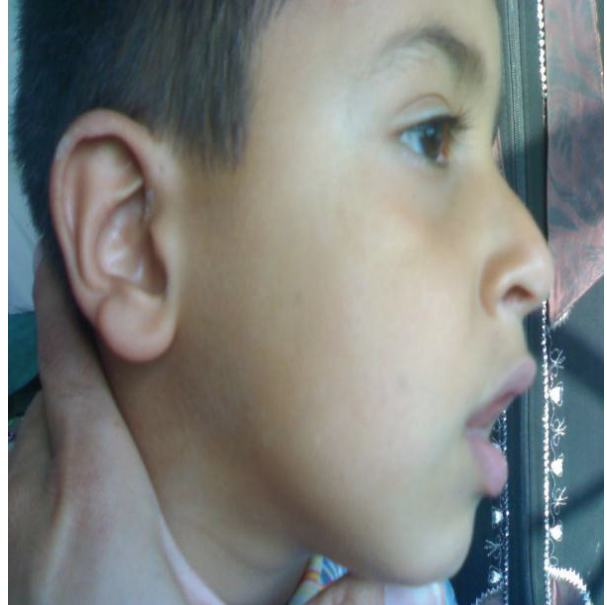

(b)

Figure 1: (a) A nine-year-old male with plane warts for 48 months duration before treatment. (b) The same patient after treatment and 3 months of followup.

Each patient was seen every two weeks during the treatment period, to assess the response to treatment and to report the side effects. The response was either any of the following.

Complete response: when there is complete disappearance of warts.

No response: when there is no or partial improvements.

For each patient the lipid profile, liver function test, and complete blood count were performed before treatment and every four weeks during the treatment period.

Followup. Patients with complete response were followed up monthly for four months to record the relapse rate.

Descriptive and analytical statistics were done by graph pad software. Chi square was used to compare the results; $P$ value of less than 0.05 was considered to be statistically significant.

\section{Results}

Twenty-six patients completed the study; their ages range from 5 to 35 with a mean \pm SD $15.28 \pm 8.51$ years. Fifteen $(57.69 \%)$ patients were females, and $11(42.30 \%)$ were males. Five patients defaulted from the study during the treatment period for unknown reasons.

The duration of warts ranged from 8-48 with a mean \pm SD $18.69 \pm 9.19$ months. Nineteen $(73.07 \%)$ patients showed complete response and seven $(26.92 \%)$ patients showed no response at the end of two months therapy. The difference was statistically significant; $P$ value $<0.0001$.

All side effects were minimal and did not require discontinuation of therapy (Table 1).

All the laboratory investigations before and during the treatment were normal for all patients.

Followup. Fifteen (78.94\%) out of 19 patients, who had complete response, were still free from warts at the end of four months followup (see Figure 1).
TABLE 1: Side effects of oral isotretinoin.

\begin{tabular}{lcc}
\hline Side effect & Number of patients & Percentage \\
\hline Dry lips & 26 & 100 \\
Dry skin & 20 & 76.92 \\
epistaxis & 2 & 7.69 \\
Dry nose & 8 & 30.76 \\
headache & 1 & 3.84 \\
\hline
\end{tabular}

\section{Discussion}

Flat warts are a common therapeutic problem. Disseminated infection on the face is, even in the immunocompetent host, a challenge [6].

Conventional therapies for human papillomavirus (HPV) infection are often associated with unsatisfactory response rates and high recurrence rates. The use of a systemic agent may more effectively control the virus [7].

Reviewing the literatures revealed that few studies that had been published showed the effectiveness of systemic isotretinoin for condylomata accuminata [5], and etretinate has been helpful for treating hyperkeratotic warts in immunosuppressed patients [8].

To our knowledge, the present study is the first that assesses the efficacy of an oral retinoid to treat plane warts.

The standard cumulative dose of oral isotretinoin for acne vulgaris is $120 \mathrm{mg} / \mathrm{kg}$; this equals to $1 \mathrm{mg} / \mathrm{kg} /$ day for four months [9]. However, this potentially high dose is associated with a high profile of side effects [10].

Many studies in the last years tried a low dose, for example, $38.4 \mathrm{mg} / \mathrm{kg}$ cumulative dose of isotretinoin in acne [10].

Other study revealed that the efficacy and relapse rates of low-dose isotretinoin $(0.5 \mathrm{mg} / \mathrm{kg} / \mathrm{day})$ in mild to moderate grades of acne are comparable with the standard regimen $(1 \mathrm{mg} / \mathrm{kg} /$ day $)[11]$.

For the above reasons and to reduce the side effects, we used a low cumulative dose of isotretinoin $(30 \mathrm{mg} / \mathrm{kg})$. 
Premature closure of epiphyses, although more common in children, is rare and occurred at higher doses [12]. Cases that had been reported with this problem are few and on long duration of therapy, for example, a 6-year-old girl with short stature which developed following the administration of 13cis-retinoic acid (isotretinoin) for 40 months [13]; other case is a boy with epidermolytic hyperkeratosis who was treated systemically for 4 and half years with 13-cis-retinoic acid. At the age of 10 and half years, he developed pain in his right knee and radiographic evidence of partial closure of the proximal epiphysis of the right tibia [14].

Comparing the results of the present study to topical imiquimod, the latter is a unique topical therapeutic agent useful in the treatment of external genital and perianal warts (condyloma acuminata) in adults. It was used in individual cases for plane warts, and it also was expensive [3].

The results of the present study were comparable to 5fluorouracil ointment, but most patients treated with the latter showed hyperpigmentation, and many of them showed erosions [4].

Pulsed dye laser treatment is a relatively effective treatment for plane warts with a clearance rate $67.6 \%$ [15]. The result was slightly lower than the present study (73.07\%). Also pulsed dye laser needs many sessions, not available widely and expensive.

Flat warts present a special therapeutic problem. Their duration may be lengthy and may be very resistant to treatment [12]. Therefore, oral isotretinoin seems to be most efficacious therapy for recalcitrant plane warts when compared with the previous studies with acceptable cost, wide availability, and it seems to be safe in children with mild and reversible side effects and no serious problems when used for a relatively short period and with a low cumulative dose.

We think that using a cumulative dose less than $30 \mathrm{mg} / \mathrm{kg}$ is of poor value, because of the expected less response and a high relapse rates. However, patients who cannot tolerate the $0.5 \mathrm{mg} / \mathrm{kg} /$ day regimen can be treated with $0.25 \mathrm{mg} / \mathrm{kg} /$ day for four months to reach the same $30 \mathrm{mg} / \mathrm{kg}$ cumulative dose with better tolerance to side effects and with a possible same response and relapse rates.

We think also that increasing the cumulative dose to $60 \mathrm{mg} / \mathrm{kg}$ for four months will result in an increase of the response and a decrease of the relapse rates, and we recommend further study using such a regimen to treat recalcitrant facial plane warts in adults who can tolerate more side effects.

\section{Conflict of Interests}

The authors declare that they have no conflict of interests. children," Journal of Dermatological Treatment, vol. 7, no. 1, pp. 21-22, 1996.

[3] R. A. Schwab and D. M. Elston, "Topical imiquimod for recalcitrant facial flat warts," Cutis, vol. 65, no. 3, pp. 160-162, 2000.

[4] S. Lee, J.-G. Kim, and S. I. Chun, "Treatment of verruca plana with 5\% 5-Fluorouracil ointment," Dermatologica, vol. 160, no. 6, pp. 383-389, 1980.

[5] M. Akyol and S. Özçelik, "Non-acne dermatologic indications for systemic isotretinoin," American Journal of Clinical Dermatology, vol. 6, no. 3, pp. 175-184, 2005.

[6] E. Weisshaar, H. J. Neumann, and H. Gollnick, "Successful treatment of disseminated facial verrucae with contact immunotherapy," European Journal of Dermatology, vol. 8, no. 7, pp. 488-491, 1998.

[7] S. Georgala, A. C. Katoulis, C. Georgala, E. Bozi, and A. Mortakis, "Oral isotretinoin in the treatment of recalcitrant condylomata acuminata of the cervix: a randomised placebo controlled trial," Sexually Transmitted Infections, vol. 80, no. 3, pp. 216-218, 2004.

[8] J. Boyle, D. C. Dick, and R. M. MacKie, "Treatment of extensive virus warts with etretinate (Tigason) in a patient with sarcoidosis," Clinical and Experimental Dermatology, vol. 8, no. 1, pp. 33-36, 1983.

[9] A. M. Layton and W. J. Cunliffe, "Guidelines for optimal use of isotretinoin in acne," Journal of the American Academy of Dermatology, vol. 27, no. 6, pp. S2-S7, 1992.

[10] K. Sardana, V. K. Garg, V. N. Sehgal, S. Mahajan, and P. Bhushan, "Efficacy of fixed low-dose isotretinoin $(20 \mathrm{mg}$, alternate days) with topical clindamycin gel in moderately severe acne vulgaris," Journal of the European Academy of Dermatology and Venereology, vol. 23, no. 5, pp. 556-560, 2009.

[11] K. Sardana and V. Garg, "Efficacy of low-dose isotretinoin in acne vulgaris," Indian Journal of Dermatology, Venereology and Leprology, vol. 76, no. 1, pp. 7-13, 2010.

[12] T. P. Habif, "Warts, herpes simplex, and other viral infections," in Clinical DermaTology. A Color Guide To Diagnosis and Therapy, vol. 12, pp. 368-408, Mosby, Philadelphia, Pa, USA, 4th edition, 2004.

[13] G. Nishimura, H. Mugishima, J. Hirao, and M. Yamato, "Generalized metaphyseal modification with cone-shaped epiphyses following long-term administration of 13-cis-retinoic acid," European Journal of Pediatrics, vol. 156, no. 6, pp. 432435, 1997.

[14] L. M. Milstone, J. McGuire, and R. C. Ablow, "Premature epiphyseal closure in a child receiving oral 13-cis-retinoic acid," Journal of the American Academy of Dermatology, vol. 7, no. 5, pp. 663-666, 1982.

[15] H. S. Park and W. S. Choi, "Pulsed dye laser treatment for viral warts: a study of 120 patients," Journal of Dermatology, vol. 35, no. 8, pp. 491-498, 2008.

\section{References}

[1] J. C. Sterling, "Virus infections," in Rook's Textbook of Dermatology, T. Burns, N. Cox, C. Griffiths, and S. Breathnach, Eds., vol. 2, pp. 25.39-31.59, Blackwell Science Ltd, Oxford, UK, 7th edition, 2004.

[2] E. P. Kubeyinje, "Evaluation of the efficacy and safety of $0.05 \%$ tretinoin cream in the treatment of plane warts in Arab 


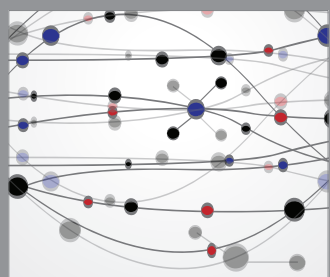

The Scientific World Journal
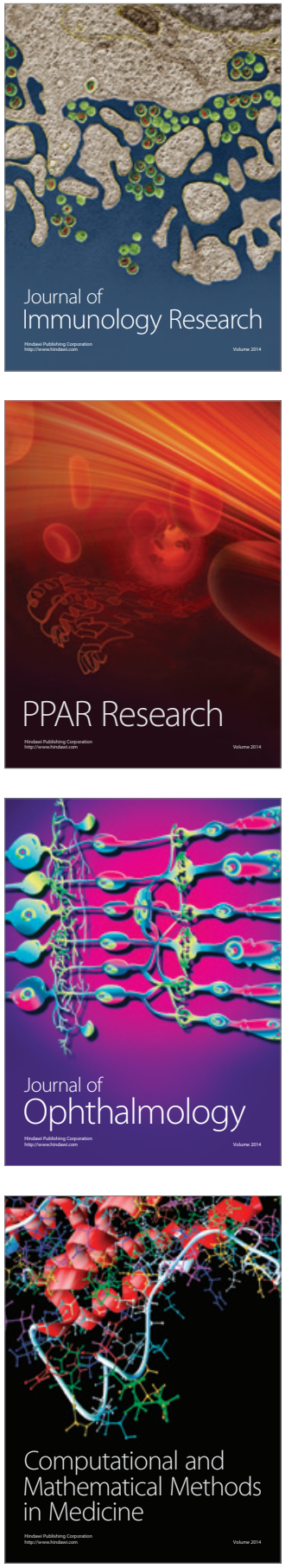

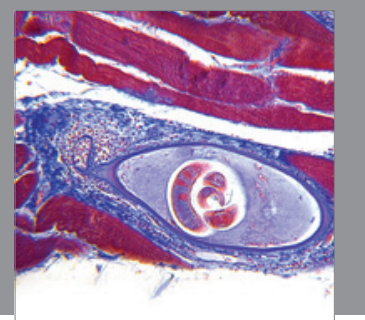

Gastroenterology

Research and Practice
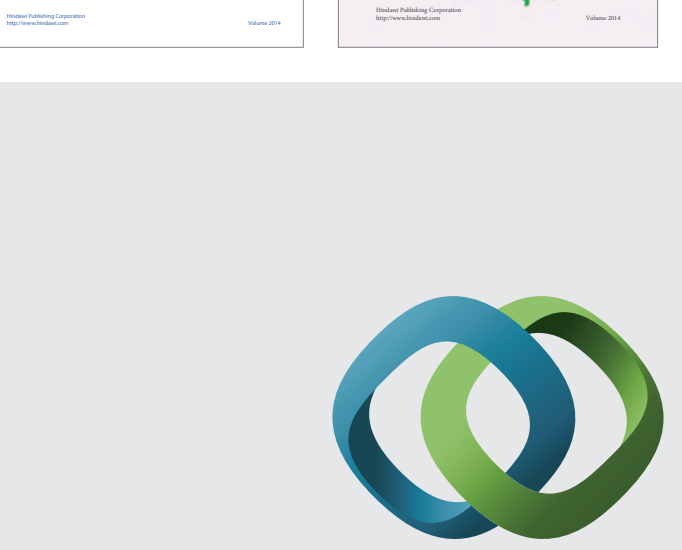

\section{Hindawi}

Submit your manuscripts at

http://www.hindawi.com
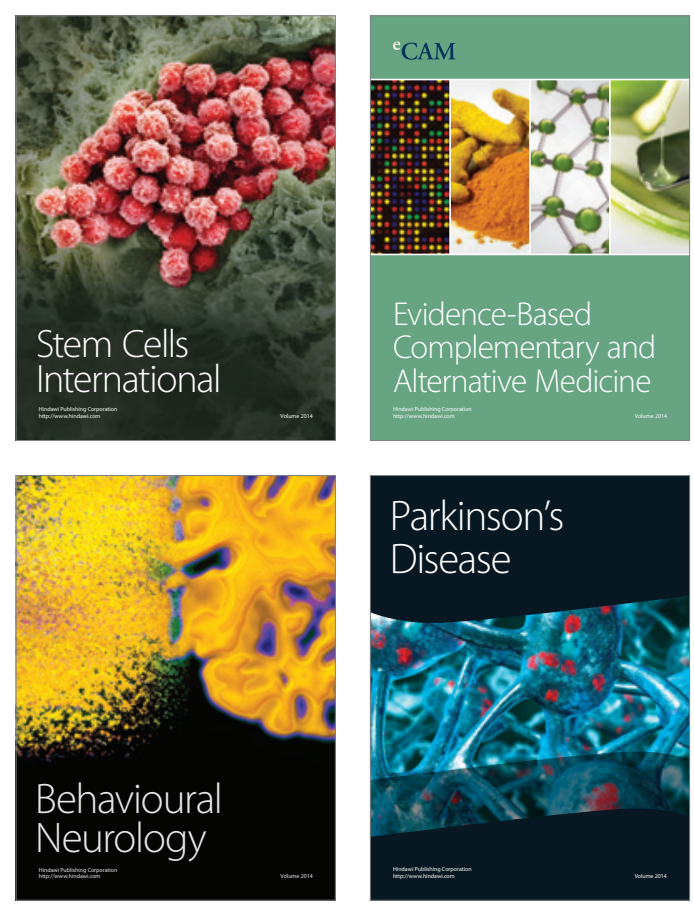

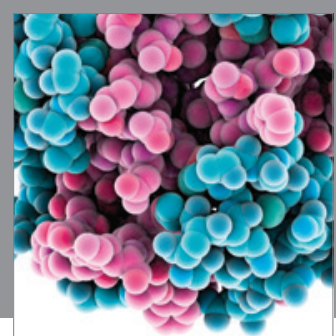

Journal of
Diabetes Research

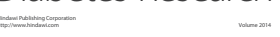

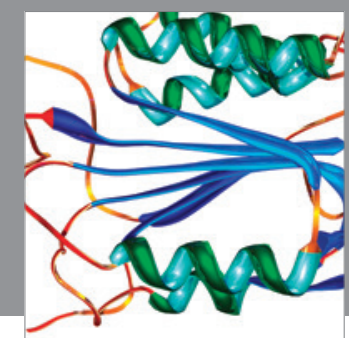

Disease Markers
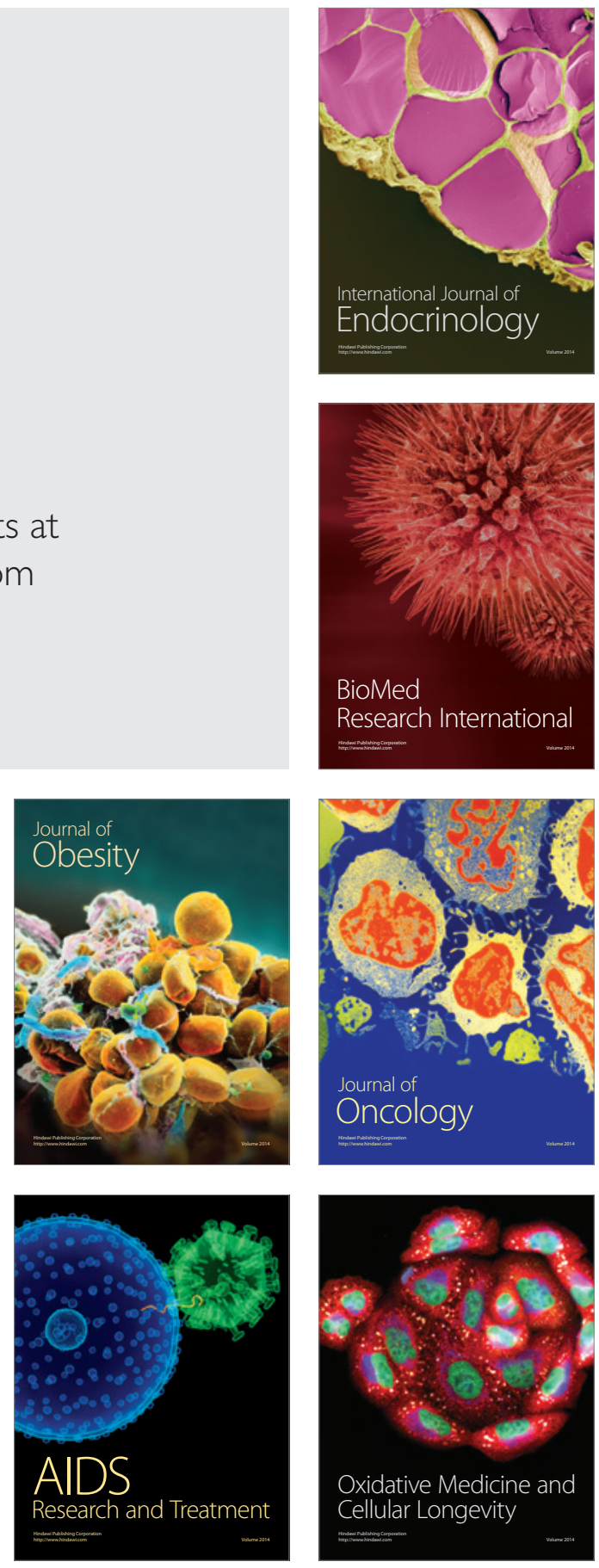